\title{
Does self-correction in the Rapid Naming Test reflect cognitive and language performance in teens?
}

\author{
Luciana Cássia de Jesus ${ }^{1}$ \\ https://orcid.org/0000-0002-0502-1578 \\ Vanessa de Oliveira Martins-Reis ${ }^{2}$ \\ https://orcid.org/0000-0002-4254-2372
}

Luciana Mendonça Alves 1

https://orcid.org/0000-0002-6403-4117

1 Universidade Federal de Minas Gerais - UFMG, Belo Horizonte, Minas Gerais, Brasil.

2 Universidade de Brasília - UnB, Brasília, Distrito Federal, Brasil.

Conflict of interests: Nonexistent

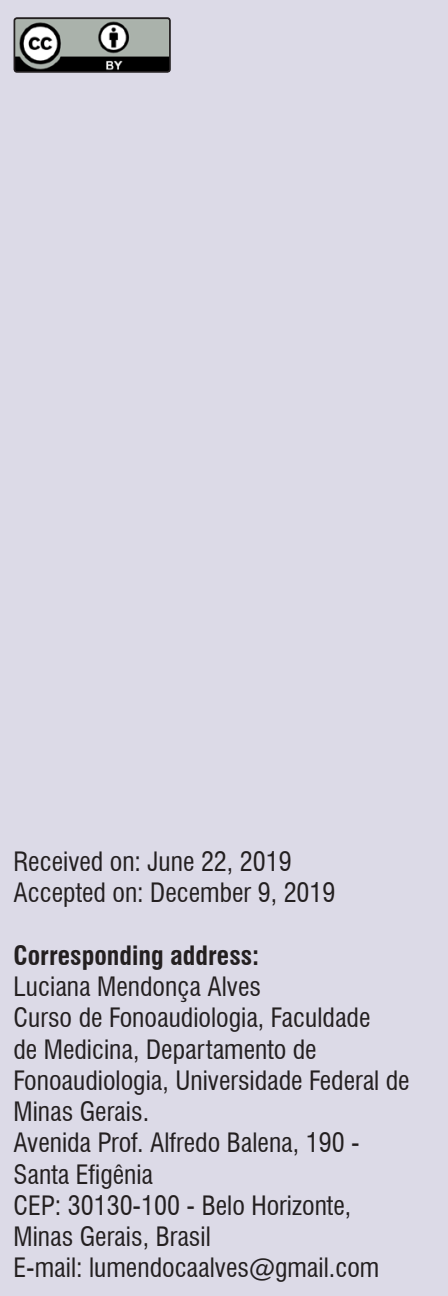

\section{ABSTRACT}

Objective: to describe the occurrence of self-correction among adolescents in the rapid automatic naming test and the influence of schooling, type of visual stimulation and cognitive and language skills.

Methods: 83 typical adolescents from 11 to 16 years old, enrolled from 6th to 9th grade of two public schools in Belo Horizonte participated in the study. The following tests were applied: rapid automatic naming, NEUPSILIN Brief Neuropsychological Assessment Instrument and Boston Naming. During rapid naming, substitutions and self-correction were accounted for. The variation in the number of errors, with and without self-correction, was related to schooling, functions and skills evaluated. Appropriate statistical tests were applied, adopting a significance level lower than 0.05 .

Results: individuals who made no mistakes had a better performance in attention, executive functions, memory, and vocabulary than those who made. Adolescents who performed self-correction were better at attention than those who did not correct themselves. Non-alphanumeric stimuli presented a higher occurrence of self-correction. Non-alphanumeric and alphanumeric tasks differed in terms of number of errors, both with and without self-correction. Adolescents from the early and late years of middle school differed regarding self-correction in the task of naming letters.

Conclusion: self-correction was frequent in the evaluated sample and differentiated the group of adolescents who self-corrected or not, regarding attention, executive functions and vocabulary.

Keywords: Adolescents; Language Tests; Language; Mental Processes 


\section{INTRODUCTION}

Rapid naming indicates the speed at which cognitive processing takes place and the efficiency with which phonological information is retrieved ${ }^{1,2}$. This process involves various cognitive resources and motor planning during visual analysis, as well as efficient retrieval of phonological $\operatorname{codes}^{3-6}$. Rapid naming also enables the assessment of attention, perception, memory, access to the mental lexicon and the speed at which processing occurs, also checking for phonological articulation and reading?.

Naming is related to oral production, which is essentially understood as access to the message conception, the sound data forming the message, and the interaction between both processes ${ }^{8}$.

The oral production process allows speech and writing to be monitored to perceive and correct words or utterances that are not following the speaker's intention and understanding. Such process, called "cognitive monitoring of speech and writing", is related to perception and attention to the recognition of errors $^{9-11}$, thus regarded as a conscious process ${ }^{9,12}$.

Levelt, in 1989, described the speech-related Perceptual Loop Theory, with the language comprehension system and the central perception as bases of the language production monitoring system. This theory is the most used in the description of speech monitoring and describes the occurrence of four steps in the process of linguistic production: conceptualization, which idealizes the information to be emitted; message formulation, which encodes information at the grammatical and phonological level; phonological articulation and self-monitoring of the producer subject ${ }^{10-12}$.

Monitoring involves internal (internal language representation) and external (auditory feedback) control mechanisms of the statement ${ }^{10,12}$, analyzing information at the output of speech production, identifies errors, processes corrections from the copy of initial language production, and forwards them to the executive motor system. Error recognition occurs on several levels, whether motor, linguistic or cognitive, all dependent on memory resources ${ }^{11,12}$. For this, the enunciate can be segmented, after identifying the error, edited with the necessary corrections and directed to the speech flow continuity ${ }^{11}$.

During picture naming, it is important to perform semantic, lexical, and phonological activation consecutively. This process is subject to failures, which result in substitutions during naming, usually corresponding to word changes related to the target word category ${ }^{8}$.
The naming of visual stimuli involves several steps. Initially, there is the visual analysis of the figure, at which time the image traces are examined and influence the next stage of recognition, as the amount of traces can help, more or less, the recognition. When there are mental representations for the image, it will be recognized by the subject. After recognition of the visual stimulus, conceptual information is accessed. This is followed by access to the denomination and sound information, which make up the name of the image and, finally, motor planning and execution ${ }^{8,13}$.

The frequency with which the stimulus occurs and the age of word acquisition in the lexicon interfere with the mental representation of the stimulus. Consequently, they reflect on the performance of naming tasks. Therefore, frequent and early acquired stimuli tend to produce stronger representations. That is, they are more resistant to interference and are more easily retrieved in memory. In addition to these factors, other data may determine naming performance, such as the amount of traits identified in the image, intimacy with stimuli, the ability to extract abstract information from the image, word length, articulatory components ${ }^{14}$ and diversity of names for the figure. Intimacy with the stimulus and the ability to extract information from the image influence semantic access and, therefore, are related to semantic errors ${ }^{8}$.

Studies show that alphanumeric stimuli have shorter naming time and are automated first than non-alphanumeric stimuli ${ }^{15,16}$ such as objects and colors, as prior access to the semantic dimension is required before stimulus naming ${ }^{17,18}$.

Age and education complement the variables reflecting on the performance of Rapid Automated Naming (RAN) test. Thus, as age and education increase, test performance also tends to increase ${ }^{15,19}$.

Similar to the rapid naming process, speech monitoring involves several cognitive resources ${ }^{11,12}$ so as to be aware of language production and repair errors when present. Thus, it is assumed that clinical analysis of self-correcting practices adds information about the individual's performance and can be observed during the rapid automatic naming task.

Some studies record the presence of corrections made by the respondents when they perceive the substitution of the stimulus name and count them as an error in the methodology, but do not argue such questions, showing the lack of consensus in the registration of answers ${ }^{2,16}$. Both rapid naming and speech monitoring need similar cognitive capabilities to be 
efficiently performed. Thus, this study aimed to describe the occurrence of self-correction among adolescents in the rapid automatic naming test, as well as the influence of education, type of visual stimulus used in the task, attention, executive functions and vocabulary.

\section{METHODS}

This is a cross-sectional, analytical and observational study, approved by the Research Ethics Committee of Federal University of Minas Gerais at Belo Horizonte, MG, Brazil, under Opinion No. 1,722,230.

\section{Casuistry}

Eighty-three adolescents, 25 males and 58 females, aged 11 to 16 years old and enrolled from 6th to 9th grade, without complaints of learning disabilities, participated in the study. All participants signed the Informed Assent Form, and their parents/guardians signed the Informed Consent Form.

Adolescents with uncorrected auditory and visual impairment, neurological, psychiatric, cognitive and learning disorders reported by their guardians were excluded.

\section{Materials and procedures}

Data were collected at two public schools in Belo Horizonte, in a quiet room provided by the school principals. The instruments were applied in two individual sessions of 40 minutes each.

All adolescents underwent the $\mathrm{RAN}^{20}$ rapid automatic naming test, the Brief Neuropsychological Assessment - NEUPSILIN ${ }^{21}$ and the Boston Naming Test $^{22}$, described below:

RAN - Consisted of four tests: color naming (red, yellow, green, blue and black), objects (umbrella, scissors, comb, clock and key), numbers (2, 4, 6, 7 and 9) and letters (A, D, O, S and P). Each board contains 5 different visual stimuli arranged randomly in 5 columns and 10 rows, totaling 50 stimuli. Errors (substitution and omission) and self-corrections were recorded and accounted for in the answers in which they were present. Substitution error was considered when the adolescent used a word that did not correspond to the image to name the test stimulus. Omission error was considered when the adolescent skipped the stimulus and did not name it. Participants were instructed to name each stimulus on the board as quickly and correctly as possible, starting from left to right, top to bottom. Before starting the test, we assured the adolescents knew all the stimuli in the test.

NEUPSILIN - Attention and executive functions tests were applied, as studies suggest the association of these functions with self-correction. The tests used to assess attention were the 30 to 0 reverse count and the repetition of digit sequences. To evaluate executive functions, verbal fluency and verbal problem-solving tests were performed, in which the adolescent should speak as many words starting with the letter $\mathrm{F}$ as he/ she remembered for one minute. In this last test we did not consider proper names, word repetitions and derived words in which the only variation was the genre, number and degree, as well as conjugations of the same verb.

Boston Naming Test - 60 figures were presented, each on a board, for the adolescents to name. The answers provided by the adolescent were recorded and the appropriate naming choices were considered correct. Semantic clues (semantic category and functional or sensory attributes) were provided when the adolescent answered incorrectly, and phonemic clues (first consonant and vowel of the word) if the adolescent kept the wrong answer. For this study, we considered the total of correct answers without clues.

\section{Data analysis}

In the descriptive statistics of the data, measures of central tendency and dispersion were used for continuous variables, and frequency tables for nominal variables.

For the analyzes, we calculated the variation in the number of errors (errors without self-correction - errors with self-correction) for each of the adolescents who presented substitution errors in the RAN. Thus, the higher the value of variation, the more self-corrections the individual makes.

Since the data did not present normal distribution (Shapiro-Wilk test), Friedman and Wilcoxon tests were used to compare the median of substitution errors when considering self-correction as error or as correctness, to verify the level of significance. Then, variables were categorized into binomial variables (self-correcting versus not self-correcting) and the effect of educational level on the use of self-corrections was verified using Fisher's Exact and Mann-Whitney tests.

To verify whether the performance of adolescents in cognitive and language skills differs between those who do or do not self-correct, the adolescents were 
divided into: "Does not perform substitution", "Does substitution and does not perform self-correction" and "Does substitution and self-correction". Then, the performance of each of these groups was compared for each cognitive and linguistic variable, using the Kruskal Wallis test. The level of significance was $5 \%$.

Figure 1 presents the flowchart with the categorization of groups for statistical analysis.

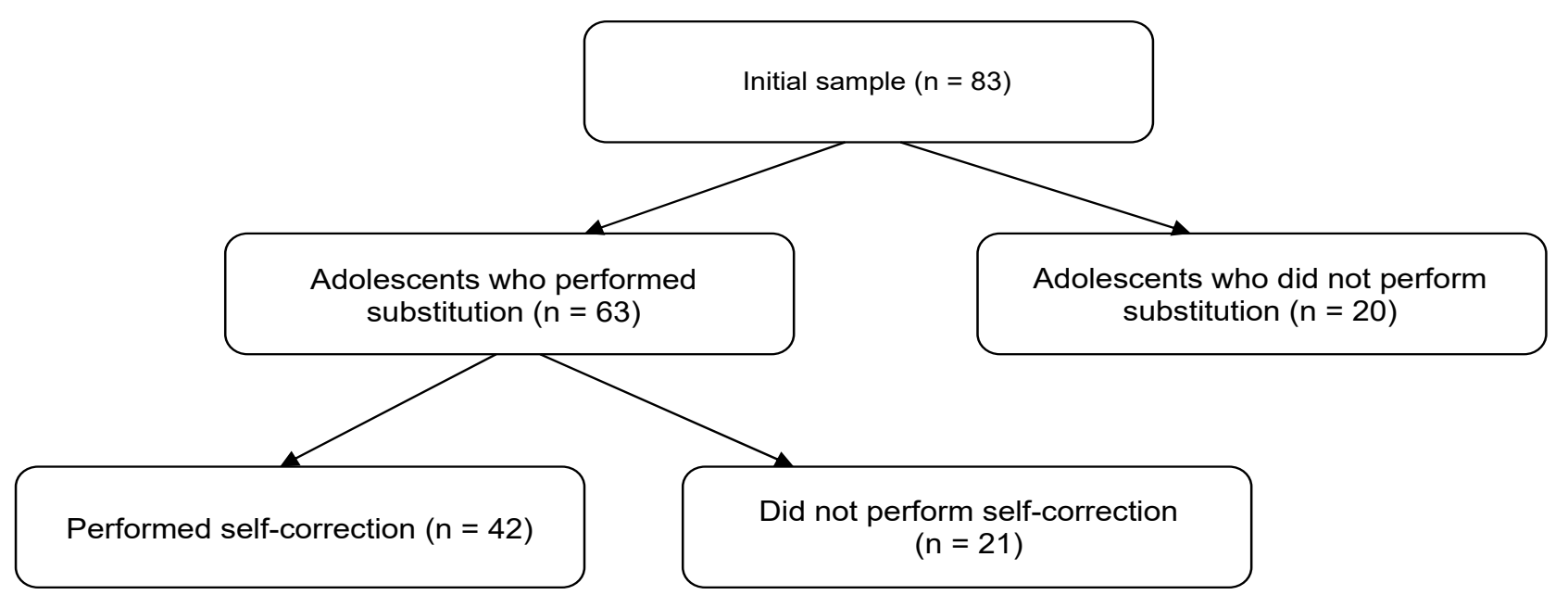

Source: Research data

Figure 1. Organization of adolescent groups for statistical analysis

\section{RESULTS}

Most adolescents in the sample $-75.9 \%(n=20)-$ performed substitutions during naming, and $24.1 \%$ $(n=20)$ correctly named all visual stimuli of the rapid automatic naming task.

\section{Effect of visual stimulus type on self-correction}

Initially, the effect of visual stimulus type on the error number variation was analyzed. For this, adolescents who did not perform substitutions were excluded. According to Table 1, the occurrence of self-correction is higher among non-alphanumeric stimuli.

Table 1. Effect of visual stimulus type on error number variation in rapid automatic naming test

\begin{tabular}{ccccc}
\hline Task & Mean & SD & Min. & Max. \\
\hline Colors & 1.19 & 1.30 & 0 & 6 \\
Objects & 1.06 & 1.17 & 0 & 5 \\
Letters & 0.29 & 0.63 & 0 & 3 \\
Digits & 0.41 & 0.75 & 0 & 4 \\
Friedman's Test (Value - p) & & Wilcoxon test (p-value) & \\
\hline Task & \multicolumn{2}{c}{0.761} \\
\hline Object - Colors & $<0.001$ & \\
Letters - Colors & $<0.001$ & \\
Digits - Colors & & $<0.001$ & \\
Letters - Objects & & $<0.001$ & \\
Digits - Objects & & 0.221 & \\
Digits - Letters & &
\end{tabular}

Caption: SD - standard deviation, Min. - Minimum, Max. - Maximum, p <0.05 


\section{Effect of schooling on self-correction}

Results of the effect of schooling on the presence and absence of self-corrections in the RAN among the adolescents who performed substitutions are presented in Table 2. The percentage of adolescents who performed self-correction by substituting the name of the visual stimulus, regardless of educational level, was high.

Table 2. Effect of education on the presence and absence of self-correction in the rapid automatic naming test in adolescents

\begin{tabular}{ccccc}
\hline \multirow{2}{*}{ Groups } & \multirow{2}{*}{ Freq. } & \multicolumn{2}{c}{ Education Level } & \multirow{2}{*}{ Total } \\
\cline { 3 - 4 } & $\mathrm{N}$ & 15 & 6 & 21 \\
Sth and 7th grade & 8th and 9th grade & 33.3 \\
\multirow{2}{*}{ Substitution without self-correction } & $\%$ & 38.5 & 25 & 42 \\
& $\mathrm{~N}$ & 24 & 18 & 66.7 \\
& $\%$ & 61.5 & 75 & 63 \\
Total & $\mathrm{N}$ & 39 & 24 & 100 \\
\hline P-value & $\%$ & 100 & 100 & \\
\hline
\end{tabular}

Caption: Freq. - frequency, $p<0.05,{ }^{*}$ Fisher's Exact Test

Color and object naming tasks had a higher frequency of self-correction than letter and digit naming tasks in all school years analyzed. However, there was a significant difference between adolescents at the beginning and end of middle school only in the task of rapid letter naming (Table 3 ).

Table 3. Effect of schooling on the variation in the number of errors in the rapid automatic naming test

\begin{tabular}{|c|c|c|c|c|c|c|c|c|c|c|c|}
\hline \multirow{2}{*}{ Task } & \multicolumn{5}{|c|}{ 6th and 7th grade $(n=39)$} & \multicolumn{5}{|c|}{ 8th and 9th grade $(n=24)$} & \multirow{2}{*}{ p-value * } \\
\hline & Mean & Median & SD & Min & Max. & Mean & Median & SD & Min & Max. & \\
\hline Colors & 1.38 & 1 & 1.49 & 0 & 6 & 0.88 & 1 & 0.85 & 0 & 2 & 0.306 \\
\hline Objects & 1.15 & 1 & 1.46 & 0 & 5 & 0.92 & 1 & 1.01 & 0 & 4 & 0.570 \\
\hline Letters & 0.15 & 0 & 0.43 & 0 & 2 & 0.50 & 0 & 0.83 & 0 & 3 & 0.045 \\
\hline Digits & 0.46 & 0 & 0.82 & 0 & 4 & 0.33 & 0 & 063 & 0 & 2 & 0.527 \\
\hline
\end{tabular}

Caption: SD - standard deviation, Min. - Minimum, Max. - Maximum, $P<0.05$, * Mann-Whitney test

\section{Effect of cognitive and linguistic skills on self-correction}

Table 4 shows the performance of each group of adolescents in the following tasks: general attention, digit sequence repetition, general executive functions, verbal fluency and vocabulary. Kruskal-Wallis test showed difference between groups for all tasks evaluated. 
Table 4. Adolescent performance in cognitive and linguistic functions according to presence and absence of substitution (error) and presence and absence of self-correction

\begin{tabular}{|c|c|c|c|c|c|}
\hline Measurements & General Attention & $\begin{array}{c}\text { Digit Sequence } \\
\text { Repeat }\end{array}$ & $\begin{array}{l}\text { General Executive } \\
\text { Functions }\end{array}$ & Verbal fluency & Vocabulary \\
\hline & \multicolumn{5}{|c|}{ No substitution and self-correction $(n=20)$} \\
\hline Mean & 24.10 & 5.15 & 6.25 & 4.90 & 46.15 \\
\hline Median & 26.00 & 6.00 & 6.00 & 5.00 & 47.50 \\
\hline SD & 3.65 & 1.81 & 1.71 & 1.48 & 6.75 \\
\hline Min. & 13 & 2 & 2 & 2 & 30 \\
\hline \multirow[t]{2}{*}{ Max. } & 27 & 7 & 10 & 8 & 55 \\
\hline & \multicolumn{5}{|c|}{ Presence of substitution without self-correction $(\mathrm{n}=21)$} \\
\hline Mean & 21.14 & 3.62 & 5.14 & 3.71 & 40.10 \\
\hline Median & 23.00 & 4.00 & 5.00 & 4.00 & 39.00 \\
\hline SD & 5.57 & 1.59 & 1.42 & 1.23 & 6.14 \\
\hline Min. & 4 & 1 & 3 & 2 & 28 \\
\hline \multirow[t]{2}{*}{ Max. } & 27 & 7 & 9 & 7 & 50 \\
\hline & \multicolumn{5}{|c|}{ Presence of substitution with self-correction ( $n=42)$} \\
\hline Mean & 23.29 & 4.67 & 5.67 & 4.40 & 42.88 \\
\hline Median & 25.00 & 5.00 & 5.00 & 4.00 & 42.50 \\
\hline SD & 4.84 & 1.79 & 1.66 & 1.59 & 6.41 \\
\hline Min. & 2 & 1 & 2 & 1 & 26 \\
\hline Max. & 27 & 7 & 10 & 8 & 56 \\
\hline P-value* & 0.017 & 0.010 & 0.030 & 0.020 & 0.010 \\
\hline
\end{tabular}

Caption: SD - standard deviation, Min. - Minimum, Max. - Maximum, * Kruskal Wallis test; $p<0.05$

The comparison between groups of adolescents, considering the presence and absence of substitution, with or without self-correction, was presented in Table 5. Those who did not substitute significantly differed in overall attention, general executive functions, and vocabulary from adolescents who perform substitution and do not correct their naming choices. Significant differences were found only in the vocabulary of adolescents who performed self-correction compared to adolescents who did not substitute, and a tendency to differentiate in executive functions was observed. Adolescents who performed substitution showed a significant difference in general attention and there was a tendency to differentiate themselves in the task of verbal fluency, and those who did self-correction performed better than those who did not self-correct but missed.

Table 5. Comparison between groups of adolescents according to the presence or absence of substitution and self-correction in cognitive and linguistic functions

\begin{tabular}{|c|c|c|c|c|c|}
\hline $\begin{array}{l}\text { Groups/ } \\
\text { P-value }\end{array}$ & $\begin{array}{l}\text { General } \\
\text { Attention }\end{array}$ & $\begin{array}{l}\text { Digit Sequence } \\
\text { Repeat }\end{array}$ & $\begin{array}{c}\text { General } \\
\text { Executive } \\
\text { Functions } \\
\end{array}$ & Verbal fluency & Vocabulary \\
\hline $\begin{array}{l}\text { No substitution versus substitution and } \\
\text { no self-correction }\end{array}$ & $0.014^{*}$ & $0.007^{*}$ & $0.006^{*}$ & $0.008^{*}$ & $0.005^{\star}$ \\
\hline $\begin{array}{l}\text { No substitution versus substitution and } \\
\text { self-correction }\end{array}$ & 0.296 & 0.209 & 0.079 & 0.150 & $0.043^{*}$ \\
\hline $\begin{array}{l}\text { Substitution and no self-correction } \\
\text { versus substitution and self-correction }\end{array}$ & $0.017^{\star}$ & $0.016^{*}$ & 0.204 & 0.073 & 0.085 \\
\hline
\end{tabular}

Caption: $p<0.05,{ }^{*}$ Mann Whitney Test 


\section{DISCUSSION}

The RAN test is crucial for the assessment of cognitive and language skills, as it provides data on information processing ${ }^{3-6}$. Some studies consider self-correction as correct during the task of naming visual stimuli of the RAN test, others regard it as an error, considering the first naming ${ }^{2,16}$. Thus, this study described the occurrence of self-correction in RAN in a group of elementary school adolescents and verified whether the performance of adolescents who do or do not correct themselves differs in attention, executive functions and vocabulary.

The ability to correct oneself shows integration between the various cognitive processes and is related to the naming of figures ${ }^{8}$. Most of the adolescents in the sample made substitution errors, suggesting they are still in the maturation phase of cognitive and linguistic processes, as failures were frequent ${ }^{8,13}$. It is noteworthy this study investigated the relationship between the occurrence of error and cognitive and linguistic factors, even though cognitive performance is influenced by other factors, such as nutrition, sleep, stress, among others ${ }^{23,24}$

Tests with alphanumeric and non-alphanumeric stimuli differed in the occurrence of self-correction, being more frequent in tests for naming objects and colors. Substitution is related to lexical access and reflects slips in the pre-lexical process of speech monitoring, at which time conceptual information is accessed ${ }^{8,14}$. These semantic errors tend to occur more frequently - especially substitution by words in the same category - and are usually detected slower than phonological errors ${ }^{14,24,25}$.

According to Levelt's theory, published in 1989, cognitive speech monitoring begins with conceptualization. In this step, information is idealized for later to be sent to the grammatical and phonological coding steps. Thus, semantic information is analyzed by the conceptual loop prior to speech articulation. In the presence of error, internal monitoring starts the repair system before the word is completely articulated. In the evaluated sample, self-monitoring was activated by the cognitive-level error detection system, which identifies errors related to the structure of thought and its translation into linguistic code ${ }^{11,12}$. This data was observed by the type of error observed - the substitution.

During visual processing of colors and objects, semantic and conceptual information is accessed before naming is performed, causing a greater overload of working memory and semantics ${ }^{7,18,26,27}$. Another impacting factor on naming performance concerns word length and articulatory complexity, which are greater in colors and objects 8,13 . Consequently, performance tends to be worse than in the naming of letters and numbers, with longer time to perform the task ${ }^{16,28}$ and may also increase the occurrence of errors.

Added to these factors, letters and numbers are automated first than colors and objects. Therefore, generally, better results are observed when naming alphanumeric stimuli ${ }^{15,29}$

Regarding education, we observed that, regardless of school year, most of the adolescents evaluated felt the need to correct themselves. However, adolescents who were in the beginning of middle school made more substitutions and self-corrections during the appointment than adolescents who attended the final years of middle school. In contrast, when comparing early and late students by stimulus type in the rapid naming task, there was a significant difference in the letter naming task.

The literature shows that advancing age and years of study improves the performance of cognitive and language skills ${ }^{17}$. Therefore, a reduction in the number of errors and better performance in cognitive speech monitoring is expected. Thus, the awareness of their own linguistic production was verified in this study, as the adolescents who attended the final years of middle school had fewer errors and, consequently, less need to repair their speech.

According to the literature ${ }^{16}$, the performance of children in the RAN test varies according to age, because as the age increases, the number of errors and the time taken to perform the test decreases. In one study, the authors verified the effect of schooling and age on processing speed and test accuracy in students from 2 nd to 5 th grade. According to the authors, 2nd grade students presented poor performance in relation to those of the other school years. Among those who had a shorter naming time, there was a smaller amount of error ${ }^{19}$.

Adolescents in the sample presented a significant difference in the naming of letters regarding the frequency of self-correction, considering they were at the beginning or end of middle school. Letter naming is a process carried out automatically by adolescents ${ }^{28}$. However, advancing age and school years have shown that adolescents are becoming more aware of their speech and can act more effectively on the monitoring system. Consequently, they can perceive and correct errors more frequently and present fewer errors ${ }^{12}$. 
Regarding cognitive performance, the evaluated adolescents who did not present substitution errors showed better performance in general attention and general executive functions (planning, cognitive flexibility, inhibitory control, memory and reasoning $)^{21}$ and vocabulary than adolescents who made mistakes and did not monitor. They also stood out in vocabulary compared to adolescents who made substitutions and corrected themselves.

Adolescents in the sample who performed substitutions and corrected themselves were better in general attention and digit sequence repetition task, which involves speech and memory sequencing, than adolescents who presented substitution errors and did not perform self-correction. Throughout the speech production process, monitoring is performed by the executive control that, depending on the attentional processes and belonging to the working memory resources, verifies whether the enunciate elaborated and produced is in accordance with the speaker's intentions and grammatical, semantic and syntactic rules ${ }^{9}$.

According to the theory of cognitive speech monitoring proposed by Flavel in 1979, one must involve cognitive and metacognitive functions for monitoring to take place ${ }^{29}$. Although cognitive speech monitoring has automatic phases, such as formulation and articulation, it is considered intentional and dependent on executive control and attention, which was verified by this study results.

Both attention and memory help in the error detection system through both auditory feedback and recognition of errors that alter the syntax of the enunciate, the structure of thought and its translation into linguistic code ${ }^{11,12}$. Attention allows the individual to focus on the essential stimulus to perform a task and inhibit irrelevant factors considered distracting, which contributes to the conscious characteristic of speech monitoring ${ }^{12}$. In a previous study conducted with neuroimaging, the activation of the left medialfrontal and temporal cortex was verified, showing the involvement of memory and language processes in speech monitoring ${ }^{10}$.

As for executive functions, they permeate the entire cognitive process and include goal selection, planning, monitoring and sequencing of actions. They are part of mental processes guided by language and participate in the process of self-regulation and metacognition of behaviors, which begins in childhood and reaches its apex in adulthood ${ }^{30}$.
Executive control, which is involved in speech monitoring, belongs to working memory resources and, because it is part of executive functions, one may suggest that speech monitoring belongs to executive functions ${ }^{9}$.

Executive functions are fundamental to the selfregulation process and enable the activation of cognitive and metacognitive strategies, so they are interpreted as internal feedback of the cognitive system and speech monitoring for the recognition and repair of errors, which was verified in this study results ${ }^{29}$.

Results of this study suggest that, for the evaluated sample, linguistic knowledge also influences the monitoring system, as recognizing that a production has broken the rules involves the individual's ability to use their linguistic knowledge.

According to scholars, the initial phase of speech monitoring process is related to message idealization and word selection, called "lexical semantic processing"14. Speech monitoring and error detection are related to language processes, since they share common brain area activations ${ }^{14}$ and vocabulary is related to language learning, cognitive skills and information processing ${ }^{31,32}$.

The literature also points out that word-level listening comprehension, which is related to vocabulary, is necessary in identifying speech errors in both inner and outer speech ${ }^{33}$. This system interacts with the production system in the search for errors, but the comprehension system acts on the production system and is triggered by speech monitoring ${ }^{12}$. Thus, speech monitoring would not only occur at the level of speech perception, but together with linguistic knowledge. Therefore, the results indicated that vocabulary may influence semantic-lexical processing since adolescents who correctly named the visual stimuli of the test presented better linguistic performance.

Results of the evaluated sample showed that awareness of linguistic production, with proper use of words, requires the proper functioning of cognitive and linguistic functions, and the ability to monitor oral production demands that the individual be aware of speech processes.

When performing self-correction, the adolescent spends more time performing the test, and time is already a measure of task recording. Thus, it can be inferred that if self-correction is accounted for as an error, it will be recorded twice: in error and time, interfering with the test results. Therefore, it is not clinically relevant to record self-correction as an error. However, 
as speech monitoring - encompassing self-correction - has been shown to be an important process during naming, which shares similar cognitive and linguistic resources, it is relevant that the assessor be aware of these processes during the assessment, as the selfmonitoring and self-correction ability during the naming test adds information about the cognitive and linguistic processes of the subject.

Due to the participant selection method, the results represent the characteristics of the evaluated adolescents, but may not represent the population of this age group, which characterizes a limitation of the study. Hence, caution is required regarding the generalization of data. Thus, further studies are needed, including samples with diverse socio-demographic and clinical profiles, to complement the data on the processes involved in self-correction and their representativeness in the RAN test.

\section{CONCLUSION}

Based on how this study was conducted, we can conclude that adolescents who correct themselves during the rapid automatic naming task perform better in general attention and inverse digit counting than those who do not correct themselves; and that adolescents who do not substitute, perform better in all assessed skills (attention, executive functions, and vocabulary) than those who do not correct themselves.

The naming of alphanumeric and non-alphanumeric stimuli differed in the frequency of self-correction, which is more present in the task of naming objects and colors. Adolescents in their early years of middle school made more self-corrections than those in their final years of middle school, differing in the task of naming letters.

\section{ACKNOWLEDGMENT}

To the Pro-Reitoria de Pesquisa (PRPq) of the Universidade Federal de Minas Gerais for the support for the publication of the study and to CAPES for providing scientific material for the research.

\section{REFERENCES}

1. Denckla MR, Cutting LE. History and significance of Rapid Automatized Naming. Ann. Dyslexia. 1999;49(1):29-42.

2. Justi CNG, Cunha N. Tarefas de nomeação seriada rápida: rastreando a dificuldade de leitura. Psic.: Teor. e Pesq. 2016;32(4):1-9.
3. Wagner RK, Torgesen JK. The nature of phonological processing and its causal role in the acquisition of reading skills. Psychol. Bull. 1987;101(2):192-212.

4. Germano GD, Pinheiro FH, Padula NAMR, Lorencetti MD, Capellini SA. Desempenho em consciência fonológica, nomeação rápida, leitura e escrita em escolares com dislexia secundária a retardo mental e com bom desempenho acadêmico. Rev. CEFAC. 2012;14(5):799-807.

5. Nicolielo AP, Hage SRV. Phonological processing in subjects with specific language impairment. Rev. CEFAC. 2014;16(6):1820-7.

6. Araújo $S$, Reis A, Petersson KM, Faísca L. Rapid automatized naming and reading performance: a meta-analysis. J. Educ. Psychol. 2015;107(3): 868-83.

7. Papadopoulos TC, Spanoudis GC, Georgiou GK. How is RAN related to reading fluency? A comprehensive examination of the prominent theoretical accounts. Front. Psychol. [internet]. 2016 [acesso em 23 de abril de 2018]; 7: artigo 1217. Disponível em: https://doi.org/10.3389/ fpsyg.2016.01217

8. Senna FD, Gomes CA. Acesso lexical na afasia. Letrônica [internet]. 2017 [acesso em 13 de novembro de 2018]; 10(2): 672-88. Disponível em: http://revistaseletronicas.pucrs.br/ojs/index.php/ letronica/article/view/26421/16574

9. Steiner VAG. Efeito da idade no monitoramento da fala [dissertação]. São Paulo (SP): Universidade de São Paulo; 2008.

10. Riès $S$, Janssen N, Dufau $S$, Alario FX, Burle B. General-purpose monitoring during speech production. J. cogn. neurosci. 2011;23(6):1419-36.

11. Werner E. Monitoramento cognitivo na produção da fala e da escrita. Rev. esc. [internet]. 2016 [acesso em 13 de novembro de 2018]; (21): [11 telas]. Disponível em:https://www.maxwell.vrac. puc-rio.br/colecao.php?strSecao $=$ resultado\& nrSeq=26586@1

12. Postma A. Detection of errors during speech production: a review of speech monitoring models. Cognition. 2000;77(2):97-131.

13. Cuetos F, Aguado G, Izura C, Ellis AW. Aphasic naming in Spanish: predictors and errors. Brain lang. 2002;82(3):344-65.

14. Abel S, Dressel K, Kümmerer D, Saur D, Mader I, Weiller $\mathrm{C}$ et al. Correct and erroneous picture 
naming responses in healthy subjects. Neurosci. lett. 2009;463(3):167-71.

15. Silva C, Capellini SA. Desempenho de escolares com e sem transtorno de aprendizagem em leitura, escrita, consciência fonológica, velocidade de processamento e memória de trabalho fonológica. Psicopedagogia. 2013;30(91):3-11.

16. Silva PB. Teste de nomeação automática rápida: evidências de validade para amostra de crianças brasileiras [dissertação]. São Paulo (SP): Universidade Presbiteriana Marckenzie; 2015 [acesso em 01 de dezembro de 2017]. Disponível em: http://tede.mackenzie.br/jspui/bitstream/ tede/2880/5/Patricia\%20Botelho\%20da\%20Silva. pdf

17. Santos MTM, Befi-Lopes DM. Vocabulário, consciência fonológica e nomeação rápida: contribuição para a ortografia e elaboração escrita. J Soc Bras Fonoaudiol. 2012;24(3):269-75.

18. Bicalho LGR, Alves LM. A nomeação rápida em escolares com e sem queixa de problemas de aprendizagem em escola pública e particular. Rev. CEFAC. 2010;12(4):608-16.

19. Lúcio PS, Kida ABS, Carvalho CAF, Cogo-Moreira $\mathrm{H}$, Ávila CRB. Prova de nomeação rápida de figuras para crianças: evidências de validade e normas intragrupo. Psico-USF. 2017;22(1):35-47.

20. Denckla MB, Rudel R. Rapid "Automatized" Naming of pictured objects, colors, letters and numbers by normal children. Cortex; 1974;10(2):186-202.

21. Fonseca RP, Salles JF, Parente MAMP. Instrumento de Avaliação Neuropsicolinguística Breve NEUPSILIN. São Paulo: Vetor Editora PsicoPedagógica, 2009.

22. Kaplan EF, Goodglass H, Weintraub S. The Boston Naming Test. Philadelphia: Lea \& Febiger, 1983.

23. Silva TM, Bueno NB, Azevedo MLSG, Clemente APG, Florêncio TMMT. Cognitive performance of stunted pre-school children undergoing nutritional recovery treatment. Rev. Paul. Pediatr. 2018; 36(1): 39-44.

24. Bawden FC, Oliveira CA, Caramelli P. Impact of obstructive sleep apnea on cognitive performance. Arq. Neuro-Psiquiatr. 2011;69(4):585-9.

25. Schuchard J, Middleton EL, Schwart MF. The timing of spontaneous detection and repair of naming errors in aphasia. Cortex [internet]. 2017 [acesso em 17 de novembro de 2018]; 93: 79-91. Disponível em: https://doi:10.1016/j.cortex.2017.05.008.
26. Schwartz MF, Middleton EL, Brecher A, Gagliardi M, Garvey K. Does naming accuracy improve through self-monitoring of errors? Neuropsychologia [internet]. 2016 [acesso em 17 de novembro de 2018]; 84:272-81. Disponível em: https:// doi:10.1016/j.neuropsychologia.2016.01.027.

27. Alves LM, Siqueira CM, Ferreira MCM, Alves JFM, Lodi DF, Bicalho $L$ et al. Rapid naming in brazilian students with dyslexia and attention deficit hyperactivity disorder. Front. Psychol [internet]. 2016 [acesso em 24 de novembro de 2018]; 7: artigo 21. Disponível em: https://doi: 10.3389/ fpsyg.2016.00021.

28. Cardoso-Martins C, Pennington BF. Qual é a contribuição da nomeação seriada rápida para a habilidade de leitura e escrita? Evidência de crianças e adolescentes com e sem dificuldades de leitura. Psicol. Reflex. Crít. 2001;14(2):387-97.

29. Deffendi LT, Shelini PW. O monitoramento metacognitivo em tarefas que envolvem a criatividade verbal. Psic.: Teor. e Pesq. 2016;32(3):1-8.

30. Tonietto L, Wagner GP, Trentini CM, Sperb TM, Parente MAMP. Interfaces entre funções executivas, linguagem e intencionalidade. Paidéia. 2011;21(49):247-55.

31. Silva RC. Compreensão de leitura e vocabulário receptivo no ensino fundamental I. [Dissertação] São Paulo (SP): Universidade de São Paulo; [acesso em 18 de dezembro de 2017]2017. Disponível em: www.teses.usp.br/teses/ disponiveis/5/5170/tde-14112017-160441/pt-br.php

32. Narlom AFO, Soares AJC, Cárnio MS. The relevance of receptive vocabulary in reading comprehension. CoDAS. 2015;27(4):333-8.

33. Ganushchak LY, Schiller NO. Detection of speech errors in the speech of others: an ERP study. Neuroimage. 2010;49:3331-7. 